\title{
Three-Dimensional Architecture of Presynaptic Terminal Cytomatrix
}

\author{
Léa Siksou, ${ }^{1}$ Philippe Rostaing, ${ }^{1}$ Jean-Pierre Lechaire, ${ }^{2}$ Thomas Boudier, ${ }^{3}$ Toshihisa Ohtsuka, ${ }^{4}$ Anna Fejtová, ${ }^{5}$ \\ Hung-Teh Kao, ${ }^{6}$ Paul Greengard, ${ }^{7}$ Eckart D. Gundelfinger, ${ }^{5}$ Antoine Triller, ${ }^{1}$ and Serge Marty ${ }^{1}$ \\ ${ }^{1}$ Inserm U789, Ecole Normale Supérieure, 75005 Paris, France, ${ }^{2}$ Service de CryoMicroscopie Electronique, Institut Fédératif de Recherche Biologie \\ Intégrative 83 Centre National de la Recherche Scientifique, Université Pierre et Marie Curie, 75252 Paris cedex 05, France, ${ }^{3}$ Imagerie Intégrative, Inserm \\ U759, Institut Curie, Bâtiment 112, Centre Universitaire Orsay, 91405 Orsay cedex, France, ${ }^{4}$ Department of Clinical and Molecular Pathology, Faculty of \\ Medicine/Graduate School of Medicine, University of Toyama, Toyama 930-0194, Japan, 5epartment of Neurochemistry and Molecular Biology, Leibniz \\ Institute for Neurobiology, 39118 Magdeburg, Germany, ${ }^{6}$ Department of Psychiatry, New York University School of Medicine, and Nathan Kline Institute \\ for Psychiatric Research, Orangeburg, New York 10962, and ${ }^{7}$ Molecular and Cellular Neuroscience, Rockefeller University, New York, New York 10021
}

Presynaptic terminals are specialized for mediating rapid fusion of synaptic vesicles (SVs) after calcium influx. The regulated trafficking of SVs likely results from a highly organized cytomatrix. How this cytomatrix links SVs, maintains them near the active zones (AZs) of release, and organizes docked SVs at the release sites is not fully understood.

To analyze the three-dimensional (3D) architecture of the presynaptic cytomatrix, electron tomography of presynaptic terminals contacting spines was performed in the stratum radiatum of the rat hippocampal CA1 area. To preserve the cytomatrix, hippocampal slices were immobilized using high-pressure freezing, followed by cryosubstitution and embedding. SVs are surrounded by a dense network of filaments. A given vesicle is connected to $\sim 1.5$ neighboring ones. SVs at the periphery of this network are also linked to the plasma membrane, by longer filaments. More of these filaments are found at the AZ. At the AZ, docked SVs are grouped around presynaptic densities. Filaments with adjacent SVs emerge from these densities. Immunogold localizations revealed that synapsin is located in the presynaptic bouton, whereas Bassoon and CAST (ERC2) are at focal points next to the AZ. In synapsin triple knock-out mice, the number of SVs is reduced by $63 \%$, but the size of the boutons is reduced by only $18 \%$, and the mean distance of SVs to the AZ is unchanged.

This 3D analysis reveals the morphological constraints exerted by the presynaptic molecular scaffold. SV s are tightly interconnected in the axonal bouton, and this network is preferentially connected to the AZ.

Key words: hippocampus; synapsin; synaptic vesicles; active zone; electron tomography; high-pressure freezing

\section{Introduction}

After a calcium influx, synaptic vesicles (SVs) fuse with the presynaptic plasma membrane, releasing their neurotransmitter content at the active zone (AZ) (Del Castillo and Katz, 1954; Heuser and Reese, 1981; Südhof, 2004; Jahn and Scheller, 2006). Some SVs must be ready to fuse for a rapid release of neurotransmitter (Schneggenburger and Neher, 2005). These "primed" SVs are likely to be docked (i.e., in contact with the AZ plasma membrane) (Harris and Sultan, 1995; Schikorski and Stevens, 1997,

Received 0ct. 17, 2006; revised May 14, 2007; accepted May 15, 2007.

This work was supported by grants from the Fondation pour la Recherche Médicale and the Fédération pour la Recherche sur le Cerveau to L.S., A.T., and S.M.; from the European Commission (SYNAPTOGENET and SynScaff) to A.T. and E.D.G.; from the State Saxony-Anhalt (N2) and the Fonds der Chemischen Industrie and by a Max Planck Award from the Humboldt Foundation and the Max Planck Society to E.D.G.; and from the National Institutes of Health (NS047209) to H.-T.K. This work was also supported by the Région lle-de-France (SESAME 95) for acquisition of the Bal-Techigh-pressure machine, the GIP-HMR program (2000; Aventis, Lyon, France) for acquisition of the TEM LE0 912 Omega cryostage, and the European network "3D-EM" to the Electron Microscopy Service Institut Fédératif de Recherche 83 Biologie Integrative. We thank Jean-Louis Bessereau for stimulating discussions.

Correspondence should be addressed to Dr. Serge Marty, Inserm U789, Ecole Normale Supérieure, 46 rue d'Ulm, 75005 Paris, France. E-mail: smarty@biologie.ens.fr.

DOI:10.1523/JNEUROSCI.1773-07.2007

Copyright $\odot 2007$ Society for Neuroscience $\quad$ 0270-6474/07/276868-10\$15.00/0
2001). A reserve pool of SVs is maintained within the bouton (Rizzoli and Betz, 2005).

Presynaptic terminals must be highly organized for the regulated trafficking of SVs. Studies using phosphotungstic acid staining showed regularly spaced dense projections at the $\mathrm{AZ}$ with docked SVs nestled between them (Gray, 1963; Pfenninger et al., 1972; Triller and Korn, 1985; Peters et al., 1991; Phillips et al., 2001; Zhai and Bellen, 2004). However, aldehyde fixatives used in these studies aggregate filaments (Gulley and Reese, 1981; Tatsuoka and Reese, 1989; Gotow et al., 1991). Quick freezing without aldehydes allowed the observation of short filaments bridging adjacent SVs and longer filaments protruding from the AZ membrane (Landis et al., 1988; Hirokawa et al., 1989; Tatsuoka and Reese, 1989; Gotow et al., 1991). The short bridges could be synapsins tethering SVs together or to the cytoskeleton (Landis et al., 1988; Hirokawa et al., 1989; Takei et al., 1995). Morphological studies of synapsin knock-out (KO) led to the notion that synapsins contribute to the maintenance of SVs at a distance from the AZ and to the shape of the bouton (Takei et al., 1995; Gitler et al., 2004). However, the spatial organization and density of filaments linking SVs together and maintaining them at the AZ has not been elucidated. 
To determine the three-dimensional (3D) architecture of the presynaptic cytomatrix, we have analyzed the distribution of SVs and filaments using electron tomography. Resolution is much improved using electron tomography compared with standard electron microscopy (Koster et al., 1997; Harlow et al., 2001; Marco et al., 2004; Lucic et al., 2005). Virtual serial sections of high $(4 \mathrm{~nm})$ resolution can be obtained from a thick object. The tissue was immobilized using high-pressure freezing (HPF; $p>$ 2100 bar), followed by cryosubstitution and embedding. HPF reduces the formation of ice crystals (Moor, 1987; Dubochet, 1995; Wilson et al., 1998; Zuber et al., 2005). HPF without aldehydes avoids the collapse of presynaptic terminals and preserves the filaments (Rostaing et al., 2006). We analyzed spine synapses in the CA1 stratum radiatum from rodent hippocampus. Our study showed the web of filaments contacting SVs. Other filaments linking this web to the plasma membrane are concentrated at the AZ. At the AZ, the docked SVs are grouped around presynaptic dense material. In agreement with previous studies, we found that $63 \%$ of SVs are lost in synapsin 1-3 triple knock-out (TKO) mice. However, the reduction in the size of presynaptic terminals is weak, and the mean distance of SVs to the AZ is unchanged, suggesting that the underlying cytomatrix is not modified.

\section{Materials and Methods}

HPF. Eight 21-d-old Sprague Dawley male rats (Janvier, Le Genest-StIsle, France) were used. In addition, three postnatal day 20 (P20) synapsin 1-3 TKO (Gitler et al., 2004) and three P20 C57BL/6 mice (Janvier) were analyzed. The protocol was as described previously (Rostaing et al., $2004,2006)$. Briefly, the rodents received an overdose of sodium pentobarbital $(150-200 \mathrm{mg} / \mathrm{kg})$. They were decapitated, and their brains were rapidly transferred to ice-cold dissection medium without calcium (Fiala et al., 2003). The hippocampus was dissected, and $400 \mu \mathrm{m}$ slices were cut perpendicular to the septotemporal axis using a McIllwain tissue chopper (Mickle Laboratory, Surrey, UK). The CA1 area of one slice was trimmed to fit in a sandwich aluminum support and was frozen in a Bal-Tec HPM 010 HPF machine, allowing an interval of $\sim 7$ min between removal of the brain and freezing. Sections from four of the rats and from the six mice were used for morphological analysis, whereas sections from three other rats were used for immunocytochemistry. The hippocampal slice from the eighth rat was incubated for $5 \mathrm{~min}$ in the dissection medium supplemented with $20 \%$ dextran and $5 \%$ sucrose before freezing (Zuber et al., 2005) and used for morphological analysis. After freezing, the sample was rapidly transferred to liquid nitrogen for storage.

Cryosubstitution and embedding. Cryosubstitution and embedding were performed in a Reichert AFS apparatus (Leica, Vienna, Austria), as described previously (Rostaing et al., 2006). Two separate protocols were used for morphological analysis and immunocytochemical analysis. Briefly, for morphological analysis, cryosubstitution was performed in acetone with $0.1 \%$ tannic acid at $-90^{\circ} \mathrm{C}$ for $4 \mathrm{~d}$, followed by acetone with $2 \%$ osmium during the last $7 \mathrm{~h}$. The slices were warmed $\left(5^{\circ} \mathrm{C} / \mathrm{h}\right)$ to $-20^{\circ} \mathrm{C}$ and incubated for 16 additional hours before being warmed $\left(10^{\circ} \mathrm{C} / \mathrm{h}\right)$ to $4^{\circ} \mathrm{C}$. At $4^{\circ} \mathrm{C}$, the slices were washed in acetone and warmed to room temperature. They were then embedded in Araldite. For immunocytochemistry, cryosubstitution was performed in methanol with $1.5 \%$ uranyl acetate at $-90^{\circ} \mathrm{C}$ for $4 \mathrm{~d}$. The slices were warmed $\left(4^{\circ} \mathrm{C} / \mathrm{h}\right)$ to $-45^{\circ} \mathrm{C}$ and embedded in Lowicryl (HM20 kit, catalog \#15924; Polysciences, Warrington, PA).

Sectioning. Ultrathin (70 nm, pale yellow) sections were cut using a Leica Ultracut UCT. Sections for immunocytochemistry were collected on formvar-coated 400-mesh nickel grids, whereas those for morphological analysis were collected on 400-mesh copper grids. For tomographic analysis, 200-nm-thick sections were collected on 400-mesh copper grids.

Immunocytochemistry. Immunocytochemistry was performed as described previously (Rostaing et al., 2006). Briefly, the sections were incu- bated for $30 \mathrm{~min}$ in blocking solution (905.002; Aurion, Wageningen, The Netherlands). After washes in incubation buffer, $0.2 \%$ BSA-c (900.099; Aurion) in PBS, the sections were incubated for $2 \mathrm{~h}$ at room temperature in incubation buffer containing antibodies against synaptophysin (1:10, A0010; DakoCytomation, Glostrup, Denmark), synapsin (1:100, antibody 1543; Chemicon, Temecula, CA), Bassoon [1:100, sap7f antibody; antibody described by tom Dieck et al. (1998)], and CAST [cytomatrix of the AZ-associated structural protein; 1:10; antibody described by Ohtsuka et al. (2002), Hagiwara et al. (2005), and DeguchiTawarada et al. (2006)]. After washes in incubation buffer, the sections were incubated for $1 \mathrm{~h}$ at room temperature in gold-conjugated secondary anti-rabbit antibodies and mouse IgG (1:50; British Biocell International, Cardiff, UK). The sections were washed, fixed in $1 \%$ glutaraldehyde (TAAB, Poole, UK) in PBS for 5 min, and washed before being air dried.

Counterstaining and examination of the sections. For morphological analysis, the sections were stained by incubation with $2 \%$ uranyl acetate in distilled water $\left(\mathrm{dH}_{2} \mathrm{O}\right)$ for $5 \mathrm{~min}$ and then with lead citrate $(0.08 \mathrm{~m}$ lead nitrate and $0.12 \mathrm{~m}$ sodium citrate in $\mathrm{CO}_{2}$-free $\mathrm{dH}_{2} \mathrm{O}$ ) for $5 \mathrm{~min}$. After immunocytochemistry, the sections were counterstained by incubation with $5 \%$ uranyl acetate in $70 \%$ methanol for $10 \mathrm{~min}$, followed by incubation with lead citrate for $3 \mathrm{~min}$. The sections were observed in a Philips TECNAI 12 (FEI, Eindhoven, The Netherlands).

Sampling of the synapses. Spine synapses were analyzed in the stratum radiatum, at $150-200 \mu \mathrm{m}$ from the stratum pyramidale. We discriminated spine synapses from shaft synapses on the basis of the small size of the postsynaptic profile and absence of mitochondria and microtubules in the postsynaptic compartment (Peters et al., 1991). As described previously, dissection of the tissue leads to alterations of the ultrastructure within $100 \mu \mathrm{m}$ of the cutting site (Rostaing et al., 2006). In addition, reticulation of the nuclei likely attributable to the formation of small ice crystals starts at $\sim 80 \mu \mathrm{m}$ from the border of the slices and increases toward the center. Large ice crystals formed in the center of the slices. We performed the analysis $60-100 \mu \mathrm{m}$ from the border of the slices, but we verified that the structure of presynaptic terminals described here was also observed (1) in the core of the slices, indicating that it did not result from tissue damage, and (2) after cryoprotection with dextran and sucrose, signifying that it was not caused by ice crystal formation.

Tomography. For tomographic analysis, thick (200 or $300 \mathrm{~nm})$ sections were incubated for $30 \mathrm{~min}$ on each side with undiluted $10 \mathrm{~nm}$ gold particles conjugated with secondary anti-rabbit antibodies (British Biocell International) and stained by incubation with $2 \%$ uranyl acetate in $\mathrm{dH}_{2} \mathrm{O}$ for $10 \mathrm{~min}$, followed by lead citrate for $10 \mathrm{~min}$. The sections were transferred to an LEO 912 electron microscope. The electron microscope was operated at $120 \mathrm{kV}$, using the in-column omega-type energy filter. Eighteen synapses were recorded with a $1024 \times 1024$ slow-scan CCD Proscan camera, at magnifications of $10,000 \times$ or $20,000 \times$ (corresponding to a pixel size of 1.7 and $0.87 \mathrm{~nm}$, respectively). Zero-loss tilted series (from approximately $-55^{\circ}$ to $+55^{\circ}$, with a $1^{\circ}$ increment) were acquired using the ESIvision program (version 3.0; Soft Imaging Software, Münster, Germany) and homemade scripts for automated acquisition [developed by the Curie Institute (S. Marco, T. Boudier, C. Messaoudi, and S. Halary) and the Electron Microscopy Service of the Integrative Biology Institute (J.-P. Lechaire) at the Unite Mixte de Recherche 7138 Centre National de la Recherche Scientifique (F. Gaill and G. Frébourg; Messaoudi et al., 2003)]. For eight of the synapses, the sections were rotated by $90^{\circ}$, and another series was acquired, allowing better imaging of the synapse because the missing information is reduced. Images of each tomographic tilt series were aligned, the tilt angle was calculated by tracking of the gold particles, and the final volume was reconstructed with a weighted back-projection algorithm, using the IMOD software for single or dual axis reconstruction (Kremer et al., 1996).

3 D reconstructions. AMIRA software (version 3.1; Mercury Computer Systems, San Diego, CA) was used for 3D reconstruction of the synapses. The contours of SVs, of the postsynaptic density (PSD), of the dense material in the synaptic cleft, or of the filaments linking the SVs, were drawn on every section. Alternatively, SVs were spotted using spheres of the corresponding diameter. The $\mathrm{AZ}$ was defined as being the presynaptic plasma membrane next to the electron-dense material filling the synaptic 

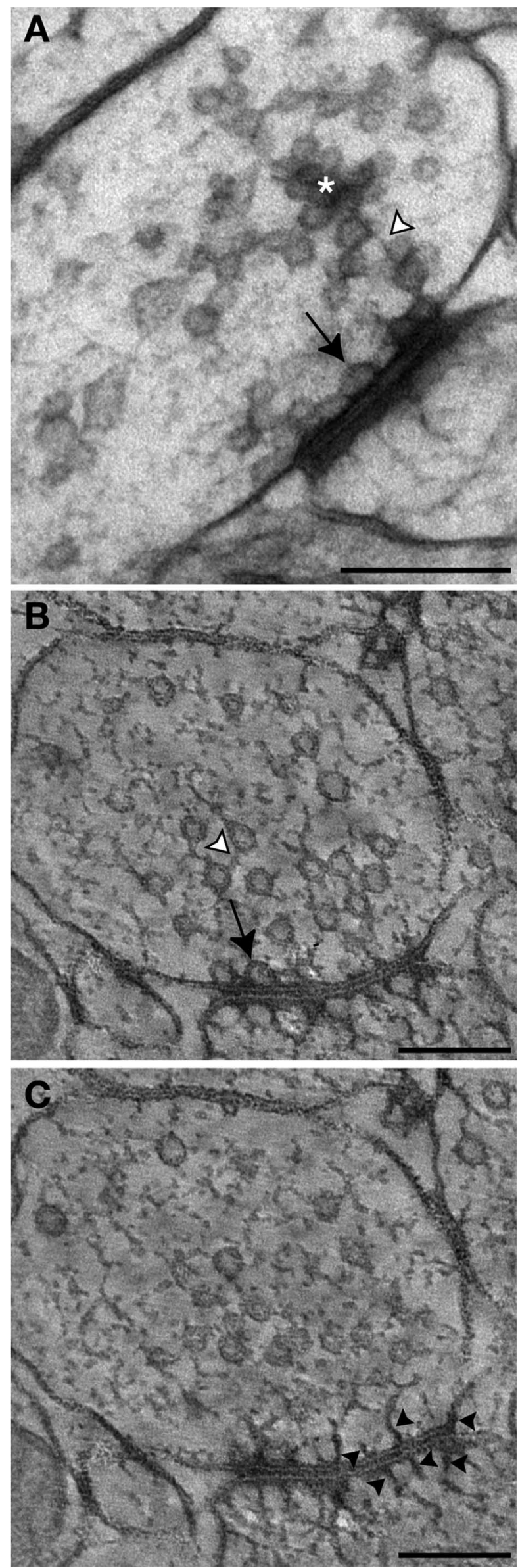

cleft and/or of the PSD. This is in line with the definition of the synaptic junction at interneuronal chemical synapses (Peters et al., 1991). We did not observe perforated synapses in our samples, likely because of their low frequency of occurrence in young animals (Harris et al., 1992). SVs were scored as "docked" when the outer layer of their membrane was contacting the inner layer of the plasma membrane.

Quantification. After immunocytochemistry, the synapses were recorded at a $43,000 \times$ magnification using a Dualvision $300 \mathrm{~W}$ camera (Gatan, Grandchamp, France). The number of gold particles and their distance to the presynaptic membrane at the $\mathrm{AZ}$ were measured on sections taken from three animals, using the ImageJ software (Abramoff et al., 2004).

After tomography, the total number of SVs was counted in 14 boutons. In 18 synapses, the surface of the PSD was measured on ImageJ, and the number of docked SVs was determined.

The number of filaments directly linking a vesicle to its neighboring SVs was counted on 52 SVs from three presynaptic boutons. The length of these filaments, as well as the length of the filaments binding the SVs to the plasma membrane, was measured on AMIRA.

For the analysis of presynaptic terminals in synapsin TKO and control mice, spine synapses were systematically digitized at a 60,000-fold magnification in two meshes of the grid, allowing analysis of 142 and 119 synapses in control and KO mice, respectively. The surface of the presynaptic profiles, the number of SVs, and their distance to the AZ were measured using ImageJ. To delineate the boundaries of the boutons, the plasma membrane of presynaptic profiles was drawn. Measurements were performed in three TKO and three control mice. An unpaired Student's $t$ test was used for statistical analysis.

\section{Results}

Synaptic morphology after HPF is different from that after aldehyde fixation (Rostaing et al., 2006). In the presynaptic terminal, SVs are less densely packed, and it becomes obvious that subgroups of SVs are interconnected via filaments (Fig. 1A). The organization of SVs within presynaptic boutons was analyzed using electron tomography. The lipid bilayers of the SVs and the plasma membrane appeared clearly on virtual sections obtained from tomograms, and the docked SVs could easily be distinguished (Fig. 1B,C). Filamentous structures (referred below as filaments) could be traced through the tomogram, and their connections with SVs or plasma membrane could be visualized. Some filaments linked the SVs to the plasma membrane, whereas others linked the SVs together. Interestingly, some presynaptic filaments ending at the AZ membrane had counterparts extending from the postsynaptic membrane. Such symmetrical presynaptic and postsynaptic filaments were observed in about half of the synapses analyzed (Fig. 1C).

\section{Organization of SVs in the presynaptic bouton}

The position of SVs was indicated using spheres of the corresponding diameter applied on tomograms. 3D reconstructions revealed that, in contrast to their apparent organization in subgroups on standard sections, SVs had a rather homogeneous distribution (see Fig. 6A).

To analyze the electron-dense meshwork surrounding SVs, the electron densities emerging from SVs were drawn on the tomographic sections (Fig. $2 A$ ), whereas electron-dense fila-

\section{$\leftarrow$}

Figure 1. Morphology of presynaptic terminals on dendritic spines after HPF. $A$, Ultrathin 70-nm-thick section. Note the presence of docked SVs (black arrow) and groups of SVs in the axonal terminal (asterisk). Filaments are observed between SVs (white arrowhead). B, C, Virtual sections from the tomographic reconstruction of a synapse. The lipid bilayer of the membranes, the docked SVs (black arrow), and the filaments between the SVs (white arrowhead) are clearly visible. Note the symmetrically arranged filaments on the presynaptic and the postsynaptic sides (black arrowheads). Scale bars, $200 \mathrm{~nm}$. 

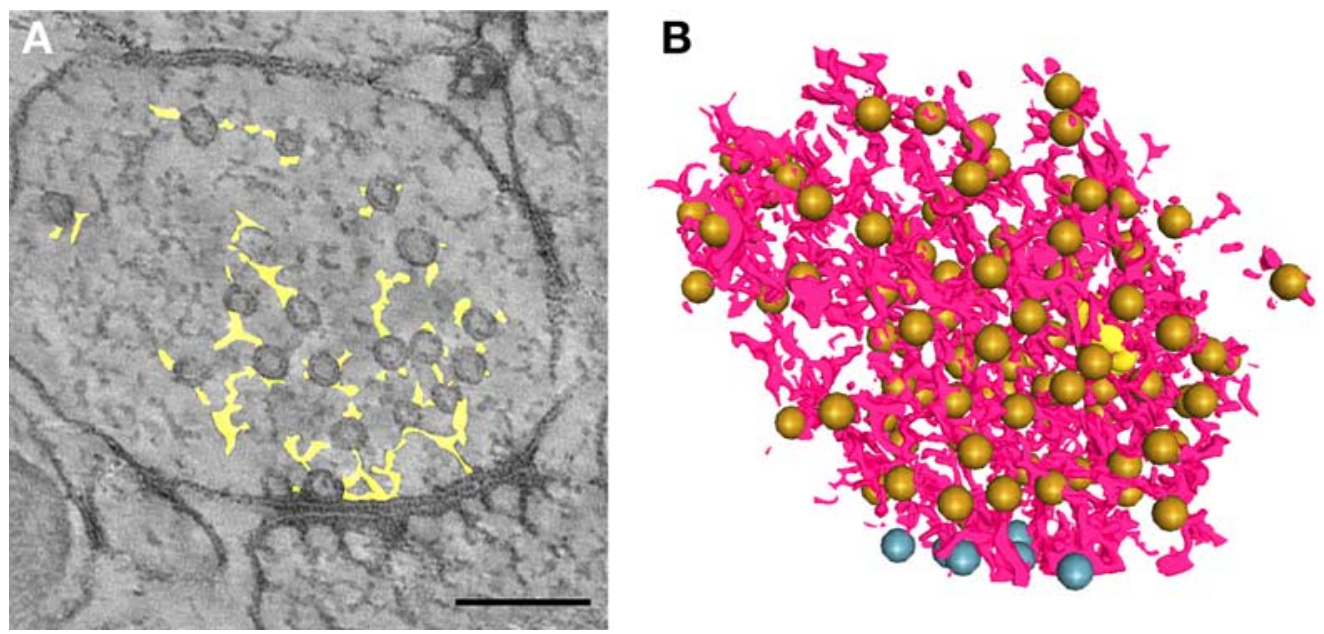

C

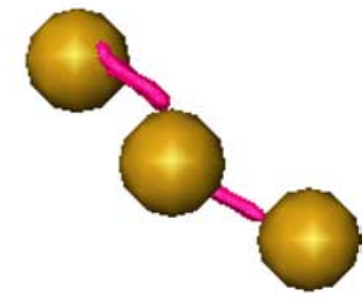

Figure 2. Network of filaments linking SVs in the presynaptic terminal. $\boldsymbol{A}$, The electron-dense materials surrounding the SVs (yellow) are superimposed on a virtual section. $\boldsymbol{B}, 3 \mathrm{D}$ reconstruction emphasizing that docked (blue) and other (gold) SVs are embedded in a tight meshwork of filaments (pink). C, Higher magnification of a partial reconstruction exemplifying the connections (pink) between neighboring SVs. Scale bar, $200 \mathrm{~nm}$.

ments not connected to SVs were ignored for this purpose. The $3 \mathrm{D}$ reconstruction over the depth of the tomogram revealed the complex network surrounding SVs (Fig. $2 B$ ). Each vesicle was directly linked to a mean of 1.5 other SVs $(n=53$ SVs analyzed) (Fig. 2C). Taking into account their 3D orientation, the size of these filaments was $32 \pm 3 \mathrm{~nm}$ (mean \pm SEM; $n=43$ ). Sometimes, the SVs were directly adjacent to each other.

\section{Links between the SVs and the presynaptic membrane}

Filaments between SVs and the plasma membrane were also observed on tomographic sections (Fig. $3 A, B$ ). The spatial organization of these filaments was traced throughout the tomograms (Fig. 3C-E). They emerged at a higher density from the plasma membrane facing the synaptic cleft (Fig. 4). The number of filaments linking SVs to the presynaptic membrane decreased, whereas the distance from the AZ increased (Fig. 5A). At synapses with a large AZ (maximal diameter, $420 \pm 30 \mathrm{~nm}$; mean \pm SEM; $n=2$ ), these filaments were all juxtaposed to the AZ (Fig. 4C), whereas at synapses with a smaller AZ $(207 \pm 24 \mathrm{~nm} ; n=4)$ (Fig. $4 D)$ they were also observed outside of the AZ. Their length was comparable independently of their origin at $(60 \pm 3 \mathrm{~nm} ; n=51)$ or outside ( $62 \pm 4 \mathrm{~nm} ; n=46)$ the AZ (Fig. $5 B, C$ ).

\section{Organization of docked SVs at the AZ}

Docked SVs were not homogeneously distributed along the AZ, as can be seen in en face views of the synapse in ultrathin sections (Fig. 6B). For a better analysis of their distribution, the docked SVs were drawn over tomograms. The PSD was also reconstructed to estimate the surface area of the AZ. The 3D reconstructions (docked SVs plus PSD) were then turned to be viewed en face (Fig. 6C). The number of docked SVs ranged between 2 and $18(7.6 \pm 1.1$; mean \pm SEM; $n=18)$. When few docked SVs were present, they tended to be grouped. Few SVs were also docked outside the AZ, although in the vicinity. In 1 of 18 instances, a group of three docked SVs was detected on the opposite side of the plasma membrane with respect to the AZ. Interestingly, the number of docked SVs was poorly correlated with the total number of SVs in a bouton (Fig. 6D). However, it was correlated ( $p<0.05 ; n=18$ ) with the size of the PSD (Fig. $6 E$ ). The total number of vesicle was not correlated with the size of the AZ (data not shown).
In tomographic serial sections, docked SVs were next to an electron-dense material clustered at the inner face of the plasma membrane (Fig. 7A-F). 3D reconstructions and surfacerendered images show that most docked SVs were in contact with these presynaptic electron-dense structures (Fig. 7G-I).

Tomographic slices and $3 \mathrm{D}$ reconstructions indicated that filaments originated from the electron densities at the AZ. Most of them contacted SVs (Fig. 7A). Some of these filaments were in contact with several SVs (Fig. $3 F-I$ ). This type of assembly was found at least once per synapse. Docked SVs were also observed next to the electron-dense material at the base of these filaments.

\section{Cartography of presynaptic proteins by immunogold localization}

HPF fixation followed by Lowicryl embedding allows the establishment of a realistic cartography of synaptic molecules (Rostaing et al., 2006). A differential localization of synaptophysin, synapsin, Bassoon, and CAST was observed. Synaptophysin was used as a marker of SVs. Its staining was distributed throughout the bouton (Fig. 8A,B). Quantitative analysis of synaptophysin distribution indicated some labeling adjacent to the presynaptic membrane, likely corresponding to docked SVs (Fig. 8). Almost no synapsin staining was observed in the first $20 \mathrm{~nm}$ from the AZ (Fig. 8), but synapsin staining was observed throughout the surface of the synaptic bouton, associated with SVs (Fig. 8C,D). In contrast, Bassoon staining was clustered, often above filaments emanating from the plasma membrane at the AZ (Fig. $8 E, F$ ). The quantification of its distribution indicated a peak at $\sim 70 \mathrm{~nm}$ (Fig. 8). CAST immunolabeling was concentrated at focal points near the AZ (Fig. 8G,H), with a peak at $\sim 30 \mathrm{~nm}$ from the AZ (Fig. 8).

\section{Organization of SVs in presynaptic boutons of synapsin TKO mice}

Synapsins have been hypothesized to maintain SVs at distance from the AZ (Pieribone et al., 1995; Takei et al., 1995; Gitler et al., 2004). Here, we have reanalyzed TKO mice for synapsins to test this hypothesis. The presynaptic boutons of synapsin TKO contained fewer SVs than those of control mice (Fig. 9A,B). Quantification indicated a $63 \%$ reduction in their number $(8 \pm 1$ vesicles per bouton in TKO vs $23 \pm 2$ in control animals; mean \pm SEM) (Fig. 9C). The surface of presynaptic terminals was reduced 

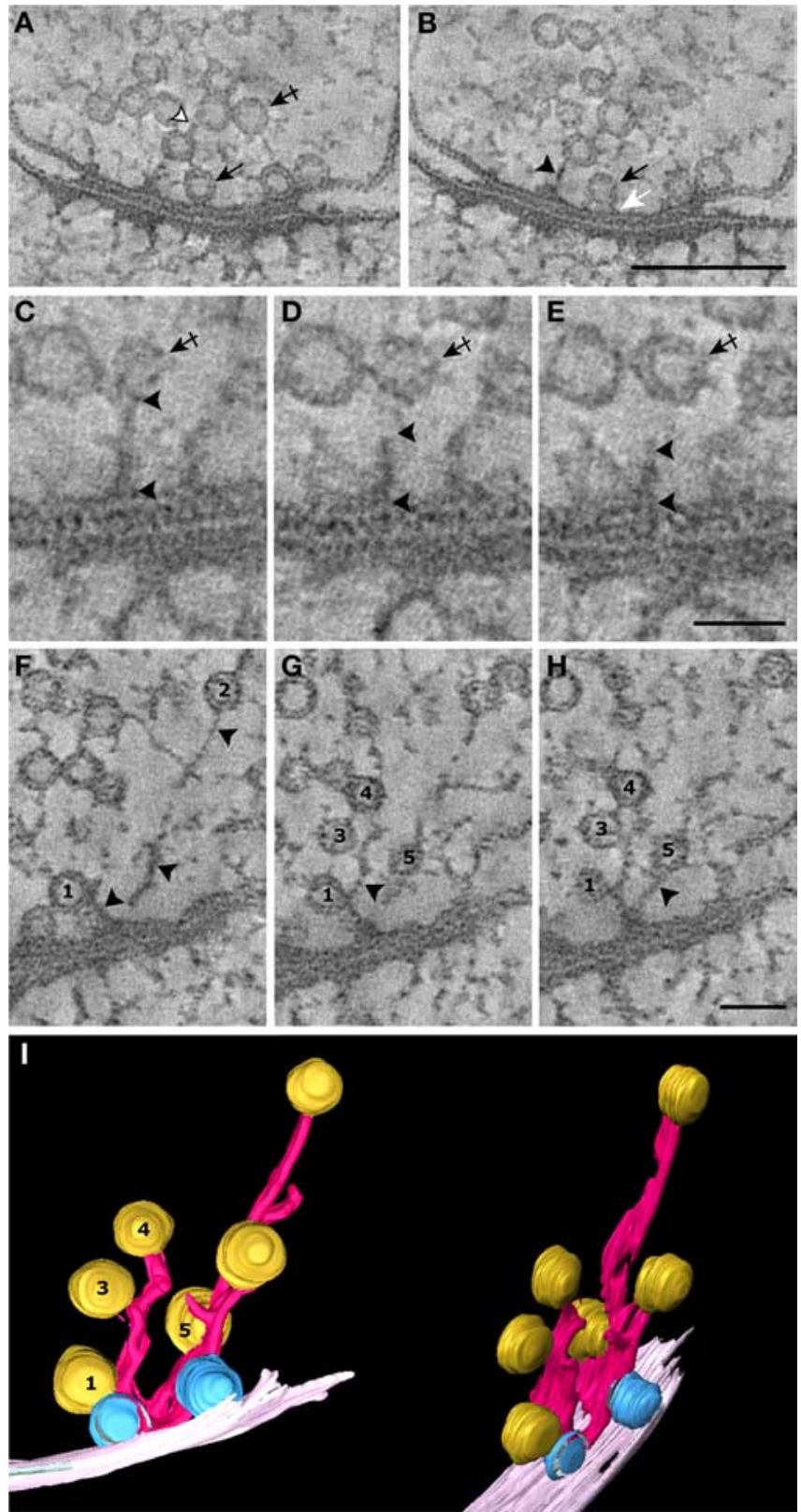

Figure 3. Filaments linking the SVs to the presynaptic membrane. $\boldsymbol{A}-\boldsymbol{E}$, Example of virtual sections through the same bouton. $\boldsymbol{A}, \boldsymbol{B}$, Low-power view with SVs either docked (arrow) or at distance (crossed arrow). Filaments interconnect SVs together (white arrowhead) or with the plasma membrane (black arrowhead). Note the short strands (white arrow) between a docked vesicle (black arrow) and the presynaptic membrane. $\boldsymbol{C}-\boldsymbol{E}$, Sequence of virtual sections (one of six serial sections) establishing the continuity of a filament (arrowheads) linking a vesicle (crossed arrow) to the presynaptic membrane. $\boldsymbol{F}-\boldsymbol{H}$, Example of a filament contacting several SVs in virtual sections through another bouton. Five SVs are in contact with a filament (arrowheads). $I, 3 D$ reconstruction of the filaments (pink) and the adjacent SVs. The SVs numbered in $\boldsymbol{I}$ are those in $\boldsymbol{F}-\boldsymbol{H}$. Scale bars: $\boldsymbol{A}, \boldsymbol{B}, 200 \mathrm{~nm} ; \boldsymbol{C}-\boldsymbol{H}, 100 \mathrm{~nm}$.

only by $18 \%$ in TKO mice (Fig. 9D). As a consequence, large parts of the bouton cytomatrix were devoid of SVs (Fig. 9B).

Despite a strong reduction in their number in synapsin TKO mice, SVs were observed within all the volume of synaptic boutons (Fig. 9B,G). On single tomographic sections, small filaments linking SVs together remained in synapsin TKO mice. Filaments between SVs and the plasma membrane were also present in TKO mice. The mean distance of SVs from the AZ was almost identical to that measured in wild-type mice (Fig. 9E). The
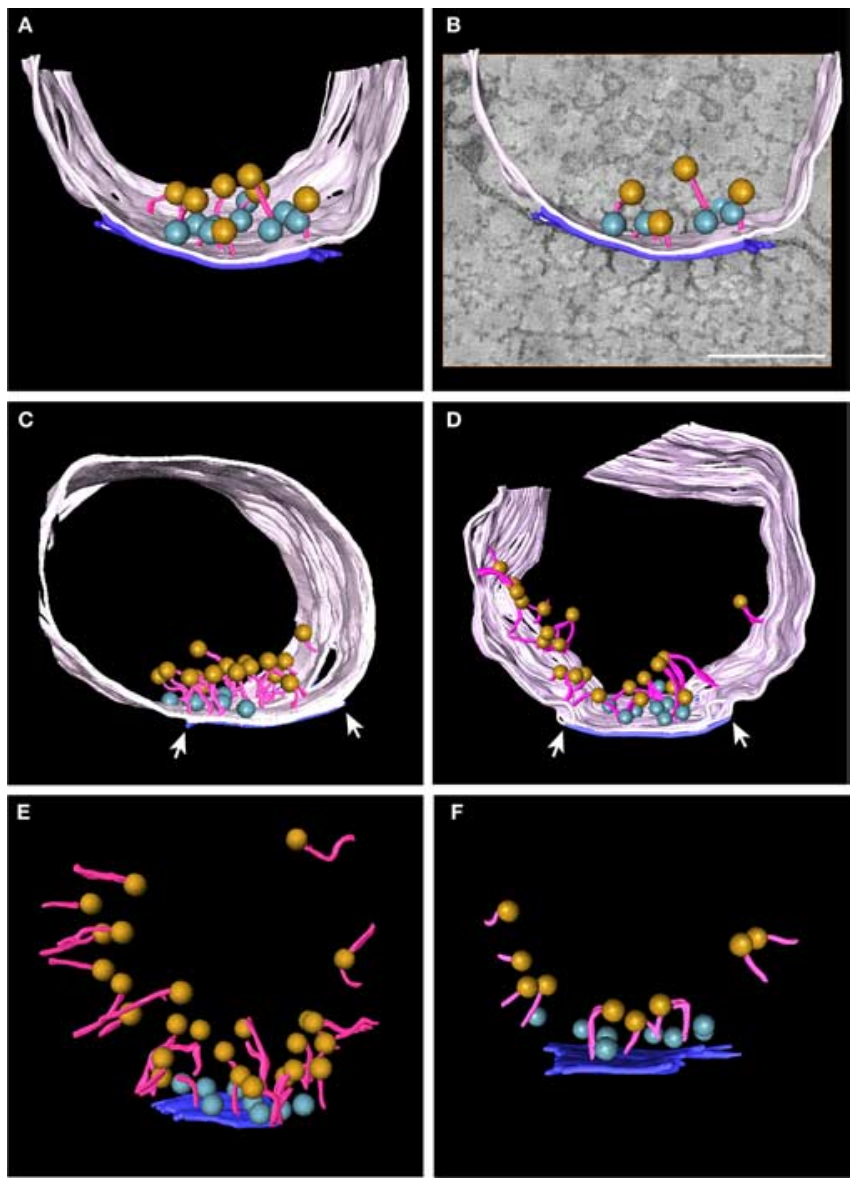

Figure 4. Distribution of the filaments linking SVs to the presynaptic membrane. $A-F, 3 D$ reconstruction of the filaments (pink) linking SVs (gold) to the plasma membrane (light pink). Docked SVs are in blue. The limits (arrows) of the synaptic junction are defined by the extension of the cleft (dark blue). $\boldsymbol{B}$ is the same synapse as in $\boldsymbol{A}$, at an intermediate stage of the reconstruction superimposed on a virtual section. $\boldsymbol{C}, \boldsymbol{D}$, Note that the filaments are more $(\boldsymbol{C})$ or less (D) concentrated at the AZ. $\boldsymbol{E}, \boldsymbol{F}$, Examples of other synapses after removal of the plasma membrane. Scale bar: $200 \mathrm{~nm}$.

number of docked vesicles in TKO and control animals was within the same range and comparable to that computed in wildtype rats (see above).

\section{Discussion}

Several aspects of the 3D architecture of the cytomatrix have been uncovered using HPF and tomographic reconstruction. Our studies revealed that SVs are interconnected via a dense meshwork of filaments with one vesicle being connected to $\sim 1.5$ nearby SVs. The network of SVs linked together by filaments is bound preferentially to the AZ by longer filaments. At the presynaptic membrane facing the synaptic cleft, docked SVs were in contact with presynaptic electron-dense structures.

The presence of filaments bridging SVs in the axonal varicosity is in agreement with several observations using quick freezing instead of aldehyde fixation (Landis et al., 1988; Hirokawa et al., 1989; Tatsuoka and Reese, 1989; Gotow et al., 1991). The length of these filaments $(30-60 \mathrm{~nm})$, together with their morphology, indicated that they might be synapsins (Landis et al., 1988; Hirokawa et al., 1989). We observed a mean length of $\sim 30 \mathrm{~nm}$ for the filaments bridging the SVs. This length is compatible with the size of synapsin molecules (Hirokawa et al. 1989). Synapsin immunoreactivity (IR) was distributed throughout the varicosities, 
A

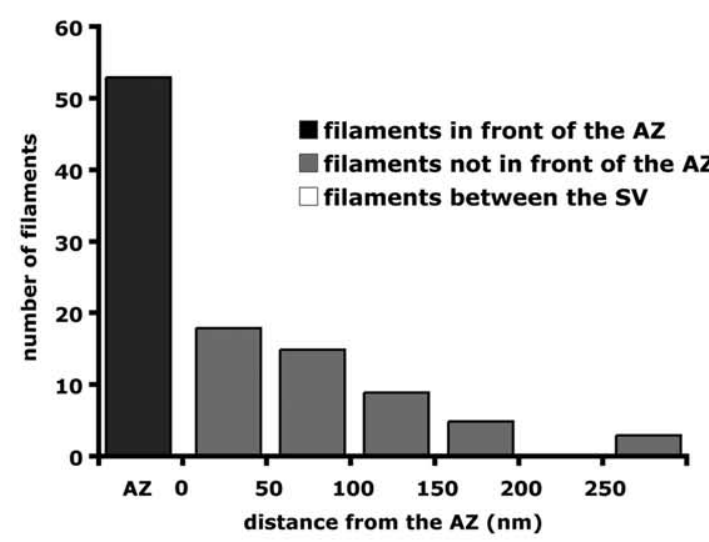

B

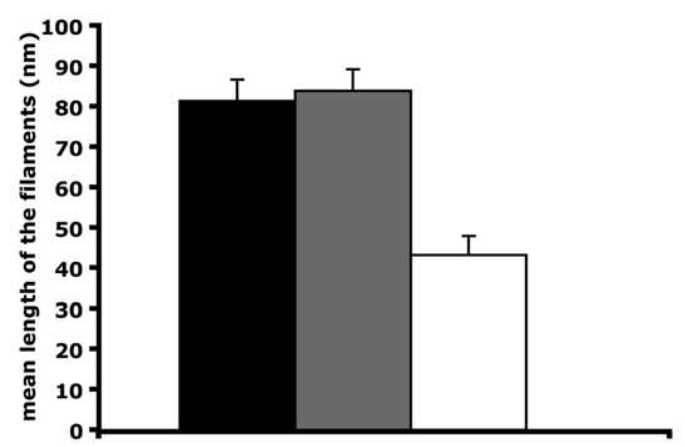

C

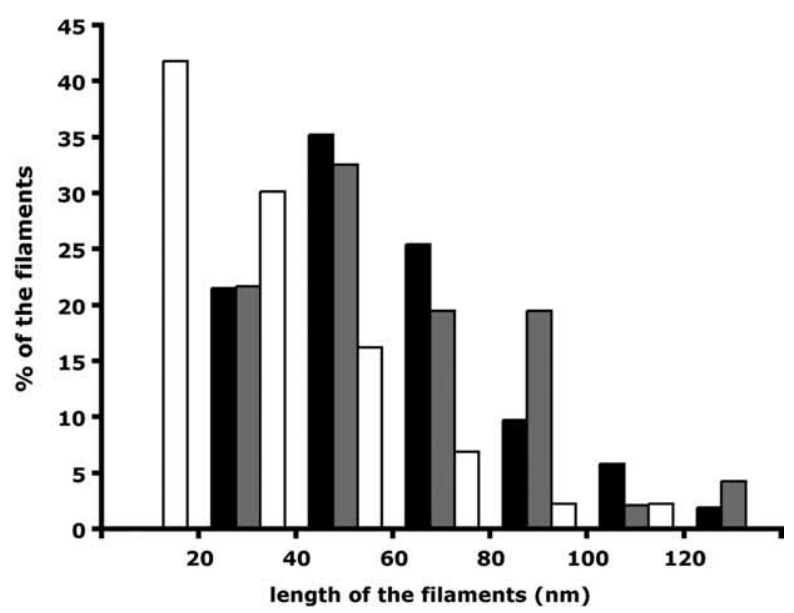

Figure 5. Quantification of the distribution and length of filaments linking the SVs together or to the plasma membrane. $A$, Distribution of the filaments linking SVs to the plasma membrane. $\boldsymbol{B}$, Filaments linking SVs to the plasma membrane are longer than those between SVs (mean \pm SEM). C, Distribution of the length of the filaments. Black bars, Filaments linking the SVs to the presynaptic membrane in front of the AZ; gray bars, filaments linking the SVs to the perisynaptic membrane; white bars, filaments linking the SVs together in the bouton.

starting from a distance of 20-40 $\mathrm{nm}$ from the presynaptic membrane. The absence of immunolabeling in the area close to the presynaptic AZ is in agreement with previous studies and compatible with the notion that synapsins are necessary for the maintenance of SVs at distance from the AZ (Pieribone et al., 1995; Takei et al., 1995; Gitler et al., 2004). Indeed, a strong reduction in the number of SVs was observed in synapsin TKO mice, starting at $100 \mathrm{~nm}$ from the AZ (Gitler et al., 2004). In accord with those studies, we also observed a strong reduction in the number of SVs
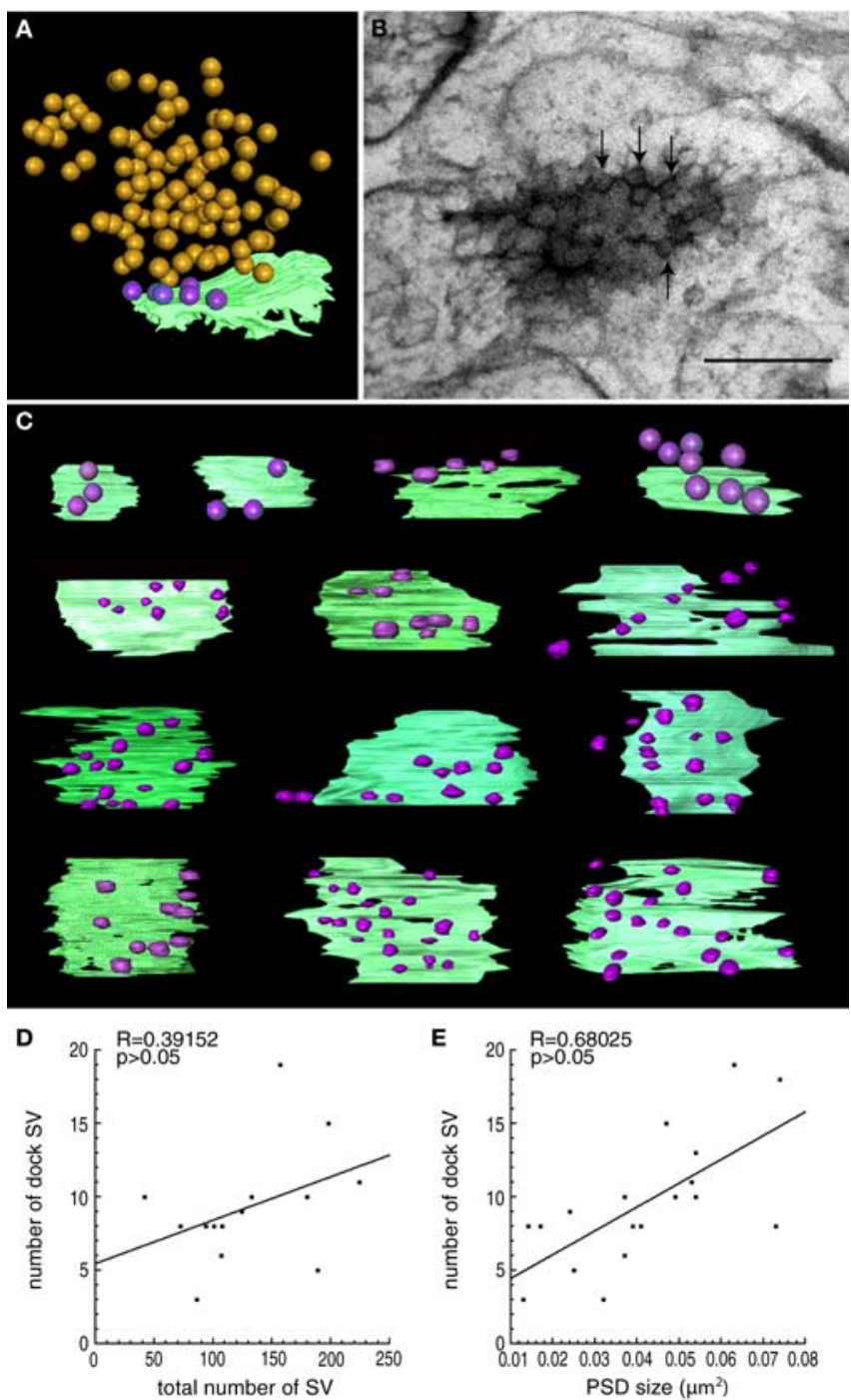

Figure 6. Distribution of the SVs. A, For 3D rendering, SVs were spotted on individual virtual sections constituting the tomogram. Docked SVs are in purple, and the other ones are in gold. The extension of the synaptic contact is defined by the PSD (green). $\boldsymbol{B}$, En face view of a synapse from an ultrathin section. The docked SVs (arrows) are not homogeneously distributed at the AZ.C, 3D reconstructions from tomograms of the docked SVs in relation to the PSD. The synapses are ordered according to the number of docked SVs. $\boldsymbol{D}$, Absence of correlation between the number of docked SVs and the total number of SVs analyzed in 14 synapses. $\boldsymbol{E}$, Correlation between the number of docked SVs and the size of the PSD in 18 synapses. Scale bar, $200 \mathrm{~nm}$.

in synapsin TKO mice. However, the mean distance of the remaining SVs to the AZ was unchanged. We did not observe a reduction in the number of SVs because the distance from the $\mathrm{AZ}$ increased. The previous observations might be attributable to aldehyde fixatives, which induce shrinkage of presynaptic terminals (Rostaing et al., 2006). Indeed, studies of presynaptic terminals in the nematode Caenorhabditis elegans showed that HPF provides a more realistic picture of the distribution of SVs than classical electron microscopy (Weimer et al., 2006). Nonetheless, we observed a moderate reduction in the size of presynaptic terminals in synapsin TKO mice, but smaller than that found using aldehydes (Takei et al., 1995). The reduction in size of presynaptic terminals was lower (18\%) than expected given the strong reduction (63\%) in SV number. Accordingly, large parts of presynaptic terminals were devoid of SVs, indicating that (1) a presynaptic cytoskeletal meshwork maintains the shape of presynaptic terminals regardless of the number of vesicles is in it and (2) 

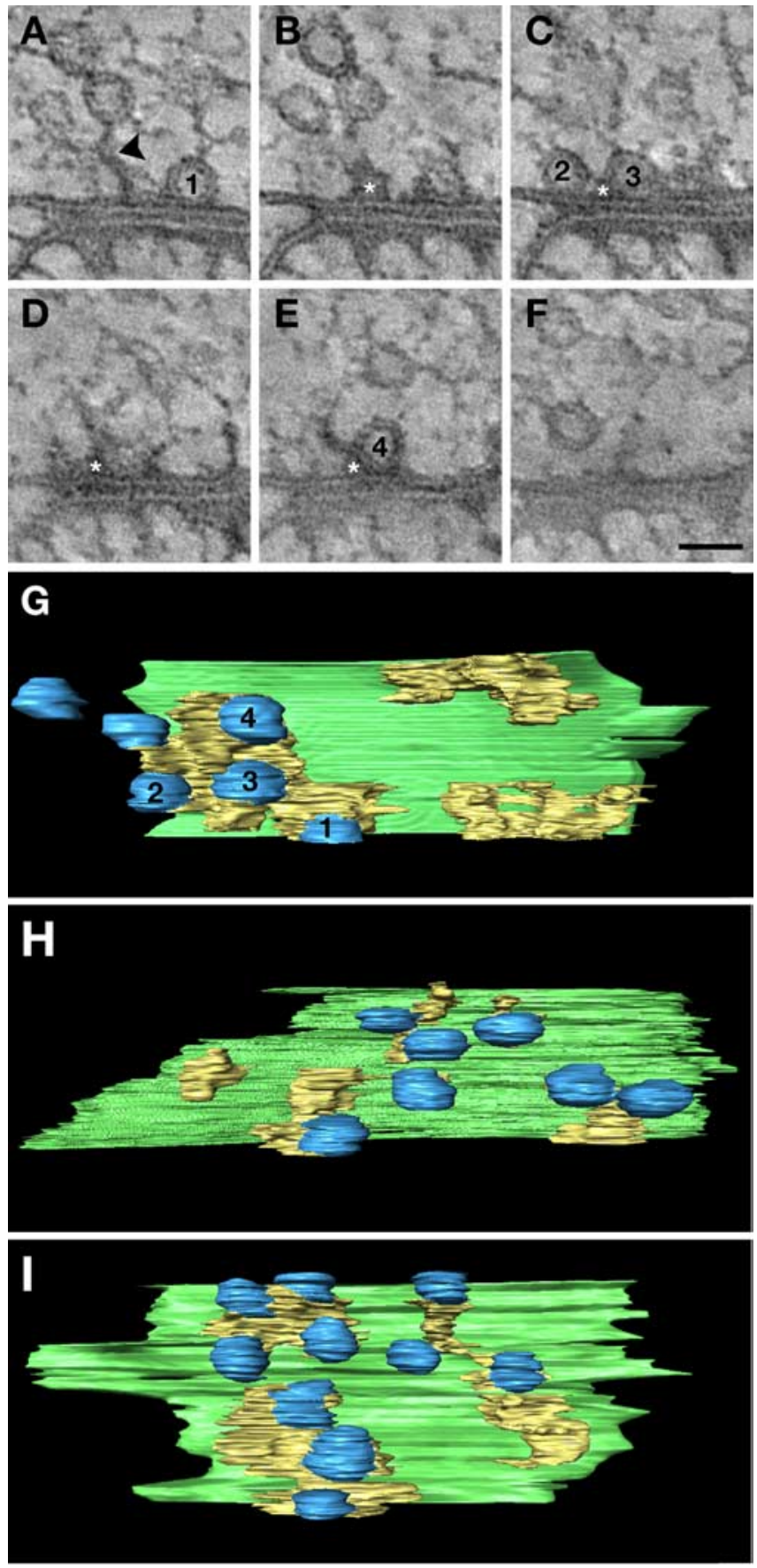

Figure 7. Association of docked SVs with presynaptic densities. $\boldsymbol{A}-\boldsymbol{F}$, Six virtual sections from a tomogram. The sections are separated by $\sim 19 \mathrm{~nm}$ in the $z$-axis. The docked SVs (numbered 1-4) are apposed to a presynaptic electron-dense material (asterisk). A filament (arrowhead) emerging from the electron-dense material contacts an SV. G-I, 3D reconstruction of the docked SVs (blue) and the presynaptic electron-dense material (yellow) in front of the PSD (green). $\boldsymbol{G}$ is the same synapse as in $\boldsymbol{A}-\boldsymbol{F}$. $\boldsymbol{H}$ and $\boldsymbol{I}$ are two other examples. Scale bars: $\boldsymbol{A}-\boldsymbol{F}, 50$ $\mathrm{nm}$.

this underlying cytomatrix does not depend on synapsin integrity. Moreover, the fact that filamentous connections between SVs can still be observed in synapsin TKO suggests that not all linking elements between SVs represent synapsins.

Within the bouton cytomatrix, tomographic analysis and 3D reconstructions revealed that a given SV is linked by filaments to $\sim 1.5$ other nearby SVs. Thus, SVs are embedded in a dense meshwork of filaments. Synapsins and other molecules bridging SVs could restrain the movement of SVs and thus explain the results of recent live imaging studies indicating that individual SVs are confined to presynaptic terminals at rest (Jordan et al., 2005; Lemke and Klingauf, 2005; Shtrahman et al., 2005; for discussion, see Gaffield et al., 2006). The connections between SVs may also explain why SVs shuttling in the axon remained grouped (Shepherd and Harris, 1998; Darcy et al., 2006). The recycling of SVs in this network could be promoted by transient dispersion of synapsins (Chi et al., 2001) and synapsin-mediated reorganization of the cytomatrix (Bloom et al., 2003) during action potentials.

We observed another population of filaments ( $\sim 60 \mathrm{~nm}$ long) that connects SVs to the plasma membrane. Therefore, these filaments, also seen using quick freezing (Landis et al., 1988; Hirokawa et al., 1989), can be distinguished from the previous ones by both their localization and their length. Their nature remains to be determined. 3D reconstructions from virtual sections obtained from tomograms now indicate that they are more abundant at the AZ than extrasynaptically. Thus, these filaments could anchor the network of bridged SVs in front of the AZ. SVs may escape from presynaptic terminals and shuttle in the axon to reach other synaptic boutons (Darcy et al., 2006). Therefore, the links between the SVs and the plasma membrane may stabilize SVs in front of the AZ. Several SVs were observed apposed along the length of some of these filaments. Thus, these filaments could provide a path for SVs toward the AZ.

Tomographic analysis revealed an association of the docked SVs with presynaptic densities at the AZ. In previous studies, tomography was used to analyze the organization of SVs with respect to presynaptic densities at saccular hair cells or at the neuromuscular junction, on material fixed with aldehydes (Lenzi et al., 1999, 2002; Harlow et al., 2001). At saccular hair cells, docked SVs were found essentially below the synaptic body and concentrated around presynaptic densities (Lenzi et al., 1999). At the neuromuscular junction, docked SVs were arranged in parallel rows, connected to a central line of dense material (or "beams") by filaments ["ribs" (Harlow et al., 2001)]. The ribs themselves contact transmembrane particles ("pegs"), which could be voltage-gated calcium channels. Thus, in this system, a regular arrangement of dense material connects docked SVs to calcium channels. The hippocampal spine synapses display a different ultrastructural organization. The docked SVs were not arranged in rows, and our observations indicated that they were grouped around focal densities, which themselves extended over only a small complement of the presynaptic membrane facing the synaptic cleft. This differs from the regularly organized dense projections visualized with phosphotungstic acid staining. This regular pattern is now thought to represent the collapse of cytoskeletal elements together and between SVs (for discussion, see Landis et al., 1988). Despite the differences in the organization of the $\mathrm{AZ}$ at peripheral and central synapses, these densities could, in both cases, serve as a coupling device associating docked SVs with calcium channels for a rapid release of the neurotransmitter in response to calcium influx.

The spatial organization of the molecular components of the cytomatrix remained to be specified. Several proteins involved in the scaffold of the presynaptic terminal have been identified (Schoch and Gundelfinger, 2006). More precisely, Piccolo, Bassoon, RIM, and CAST (also known as ERC2) form a complex localized at the cytomatrix associated with the AZ (CasesLanghoff et al., 1996; Wang et al., 1997, 2002; tom Dieck et al., 1998; Ohtsuka et al., 2002; Takao-Rikitsu et al., 2004; Hagiwara et al., 2005; Weimer et al., 2006). We have mapped the distribution of synaptophysin-, synapsin-, Bassoon-, and CAST-IR with re- 

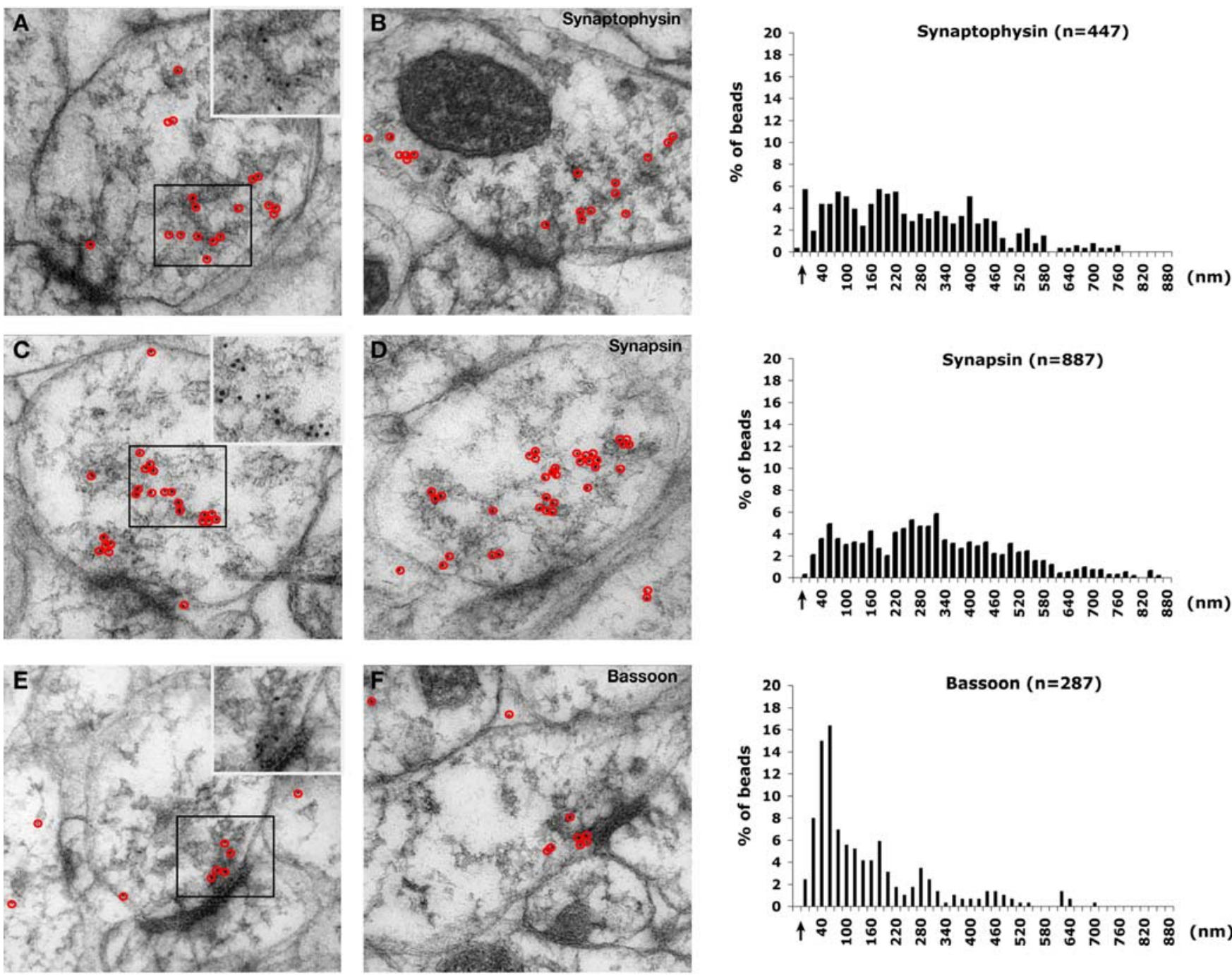

$(\mathrm{nm})$
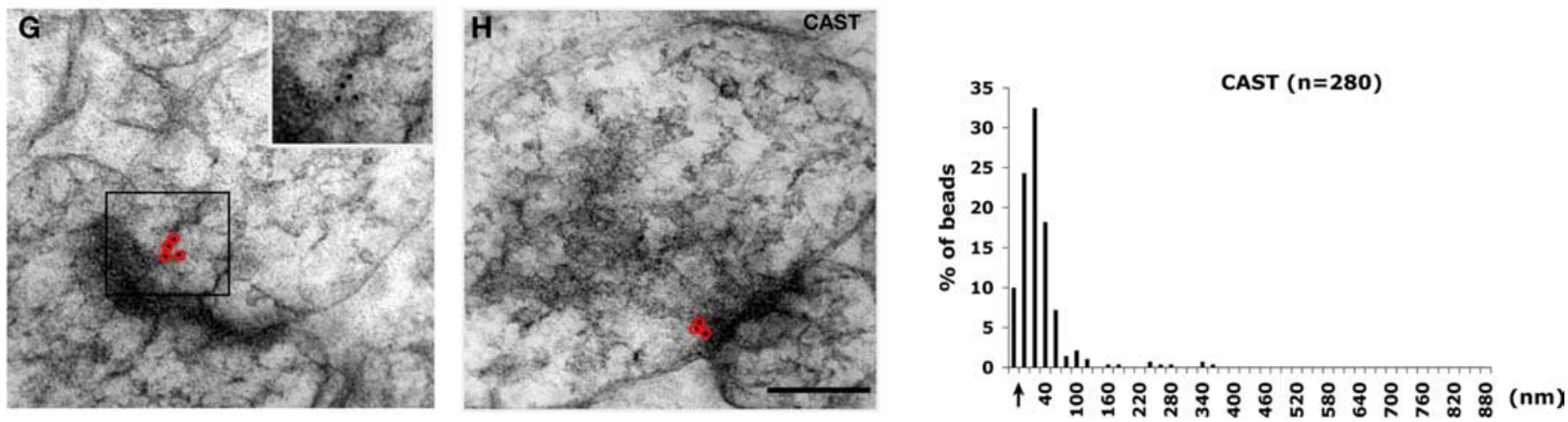

Figure 8. Postembedding immunocytochemistry of presynaptic proteins on ultrathin sections. The immunogold particles are circled in red. The insets show the gold particles. $A, B, S y n a p t o p h y-$ $\sin . \boldsymbol{C}, \boldsymbol{D}$, Synapsin. $\boldsymbol{E}, \boldsymbol{F}$, Bassoon. $\boldsymbol{G}, \boldsymbol{H}$, CAST. Histograms, for the indicated antigens, of the percentage of gold particles as a function of their distance to the membrane (bin, $20 \mathrm{~nm}$ ) are shown. The arrow indicates the position of the presynaptic membrane. $n$ is the number of gold particles analyzed. Scale bars, $200 \mathrm{~nm}$.

spect to the presynaptic membrane at the AZ. Synaptophysin-IR [a transmembrane SV protein (Südhof et al., 1987)] was used as a generic marker of SVs. CAST-, Bassoon-, and synapsin-IR had a sequential distribution relative to the AZ. Our observations indicate that CAST-IR is closer to the plasma membrane than Bassoon-IR. It has been shown that CAST directly interacts with Bassoon (Takao-Rikitsu et al., 2004). The interaction of CAST and Bassoon at spine synapses might be very similar to that taking place at the ribbon synapse. Indeed, at ribbon synapses, CAST is located near the AZ plasma membrane and could be linked to more distant proteins by Bassoon (tom Dieck et al., 2005). The ultrastructure of presynaptic boutons is normal in mutant mice expressing a Bassoon protein lacking the region implicated in its anchoring to the AZ (Altrok et al., 2003). However, the structurally related protein Piccolo may exert a function similar to that of Bassoon (Fenster et al., 2000). In the retina from Bassoon $\mathrm{KO}$ mice, the ribbon at the photoreceptor synapse is detached from the presynaptic membrane (Dick et al., 2003). This indicates that 

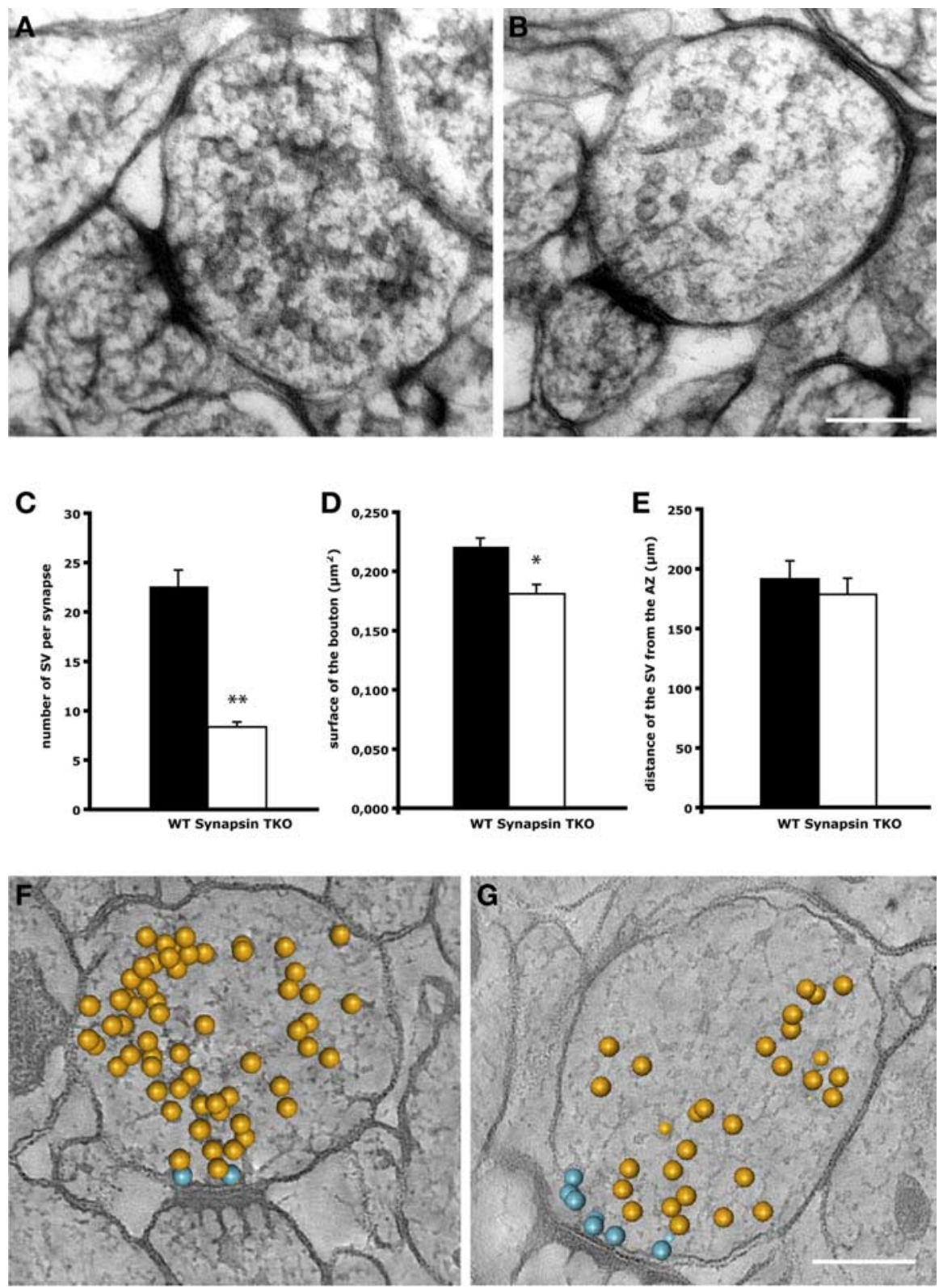

Figure 9. Morphology of presynaptic terminals in synapsin TKO mice. $\boldsymbol{A}, \boldsymbol{B}$, Ultrathin sections of control $(\boldsymbol{A})$ and TKO $(\boldsymbol{B})$ mice. $C$, The number of SVs is reduced in TKO mice (mean \pm SEM; $p<0.01$, Student's $t$ test). $D$, The area of presynaptic profiles is reduced in TKO mice $(p<0.05)$. $\boldsymbol{E}$, The mean distance of SVs from the AZ is not changed. $\boldsymbol{F}, \mathbf{G}$, Distribution of SVs spotted on tomograms from sections of control $(\boldsymbol{F})$ or TKO $(\boldsymbol{G})$ mice. Scale bars, $200 \mathrm{~nm}$.

Bassoon has a role in anchoring the ribbon to the presynaptic AZ. CAST is also involved in the architecture of presynaptic terminals. Bruchpilot, the Drosophila homolog of CAST, is necessary for the formation or maintenance of the presynaptic densities (T bars) at Drosophila neuromuscular junctions (Kittel et al., 2006; Wagh et al., 2006). At hippocampal synapses, these proteins could be involved in the formation of the filamentous links between SVs and the AZ, or of the presynaptic densities at the AZ. Whatever its molecular organization, the $3 \mathrm{D}$ architecture of the cytomatrix within the presynaptic terminals revealed in this study emphasizes the morphological constraints by which the molecular scaffold maintains SVs in front of the AZ and organizes their release at particular areas of the presynaptic membrane.

\section{References}

Abramoff MD, Magelhaes PJ, Ram SJ (2004) Image processing with ImageJ. Biophotonics Int 11:36-42.
Altrock WD, tom Dieck S, Sokolov M, Meyer AC, Sigler A, Brakebusch C, Fassler R, Richter K, Boeckers TM, Potschka H, Brandt C, Loscher W, Grimberg D, Dresbach T, Hempelmann A, Hassan H, Balschun D, Frey JU, Brandstatter JH, Garner CC, et al. (2003) Functional inactivation of a fraction of excitatory synapses in mice deficient for the active zone protein bassoon. Neuron 37:787-800.

Bloom O, Evergren E, Tomilin N, Kjaerulff O, Low P, Brodin L, Pieribone VA, Greengard P, Shupliakov O (2003) Colocalization of synapsin and actin during synaptic vesicle recycling. J Cell Biol 161:737-747.

Cases-Langhoff C, Voss B, Garner AM, Appeltauer U, Takei K, Kindler S, Veh RW, De Camilli P, Gundelfinger ED, Garner CC (1996) Piccolo, a novel $420 \mathrm{kDa}$ protein associated with the presynaptic cytomatrix. Eur J Cell Biol 69:214-223.

Chi P, Greengard P, Ryan TA (2001) Synapsin dispersion and reclustering during synaptic activity. Nat Neurosci 4:1187-1193.

Darcy KJ, Staras K, Collinson LM, Goda Y (2006) Constitutive sharing of recycling synaptic vesicles between presynaptic boutons. Nat Neurosci 9:315-321.

Deguchi-Tawarada M, Inoue E, Takao-Rikitsu E, Inoue M, Kitajima I, Ohtsuka T, Takai Y (2006) Active zone protein CAST is a component of conventional and ribbon synapses in mouse retina. J Comp Neurol 495:480-496.

Del Castillo J, Katz B (1954) Quantal components of the end-plate potential. J Physiol (Lond) 124:560-573.

Dick O, tom Dieck S, Altrock WD, Ammermüller J, Weiler R, Garner CC, Gundelfinger ED, Brandstätter JH (2003) The presynaptic active zone protein Bassoon is essential for photoreceptor ribbon synapse formation in the retina. Neuron 37:775-786.

Dubochet J (1995) High-pressure freezing for cryoelectron microscopy. Trends Cell Biol 5:366-368.

Fenster SD, Chung WJ, Zhai R, Cases-Langhoff C, Voss B, Garner AM, Kaempf U, Kindler S, Gundelfinger ED, Garner CC (2000) Piccolo, a presynaptic zinc finger protein structurally related to Bassoon. Neuron 25:203-214.

Fiala JC, Kirov SA, Feinberg MD, Petrak LJ, George P, Goddard CA, Harris KM (2003) Timing of neuronal and glial ultrastructure disruption during brain slice preparation and recovery in vitro. J Comp Neurol 465:90-103.

Gaffield MA, Rizzoli SO, Betz WJ (2006) Mobility of synaptic vesicles in different pools in resting and stimulated frog motor nerve terminals. Neuron 51:317-325.

Gitler D, Takagishi Y, Feng J, Ren Y, Rodriguiz RM, Wetsel WC, Greengard P, Augustine GJ (2004) Different presynaptic roles of synapsins at excitatory and inhibitory synapses. J Neurosci 24:11368-11380.

Gotow T, Miyaguchi K, Hashimoto PH (1991) Cytoplasmic architecture of the axon terminal: filamentous strands specifically associated with synaptic vesicles. Neuroscience 40:587-598.

Gray EG (1963) Electron microscopy of presynaptic organelles of the spinal cord. J Anat 97:101-106.

Gulley RL, Reese TS (1981) Cytoskeletal organization at the postsynaptic complex. J Cell Biol 91:298-302.

Hagiwara A, Fukazawa Y, Deguchi-Tawarada M, Ohtsuka T, Shigemoto R (2005) Differential distribution of release-related proteins in the hippocampus CA3 area as revealed by freeze-fracture replica labeling. J Comp Neurol 489:195-216.

Harlow ML, Ress D, Stoschek A, Marshall RM, McMahan UJ (2001) The 
architecture of active zone material at the frog's neuromuscular junction. Nature 409:479-484.

Harris KM, Sultan P (1995) Variation in the number, location and size of synaptic vesicles provides an anatomical basis for the nonuniform probability of release at hippocampus CA1 synapses. Neuropharmacology 34:1387-1395.

Harris KM, Jensen FE, Tsao B (1992) Three-dimensional structure of dendritic spines and synapses in rat hippocampus (CA1) at postnatal day 15 and adult ages: implications for the maturation of synaptic physiology and long-term potentiation. J Neurol 12:2685-2705.

Heuser JE, Reese TS (1981) Structural changes after transmitter release at the frog neuromuscular junction. J Cell Biol 88:564-580.

Hirokawa N, Sobue K, Kanda K, Harada A, Yorifuji H (1989) The cytoskeletal architecture of the presynaptic terminal and molecular structure of synapsin 1. J Cell Biol 108:111-126.

Jahn R, Scheller RH (2006) SNAREs-engines for membrane fusion. Nat Rev Mol Cell Biol 7:631-643.

Jordan R, Lemke EA, Klingauf J (2005) Visualization of synaptic vesicle movement in intact synaptic boutons using fluorescence fluctuation spectroscopy. Biophys J 89:2091-2102.

Kittel RJ, Wichmann C, Rasse TM, Fouquet W, Schmidt M, Schmid A, Wagh DA, Pawlu C, Kellner RR, Willig KI, Hell SW, Buchner E, Heckmann M, Sigrist SJ (2006) Bruchpilot promotes active zone assembly, Ca2+ channel clustering, and vesicle release. Science 312:1051-1054.

Koster AJ, Grimm R, Typke D, Hegerl R, Stoschek A, Walz J, Baumeister W (1997) Perspectives of molecular and cellular electron tomography. J Struct Biol 120:276-308.

Kremer JR, Mastronarde DN, McIntosh JR (1996) Computer visualization of three-dimensional image data using IMOD. J Struct Biol 116:71-76.

Landis DM, Hall AK, Weinstein LA, Reese TS (1988) The organization of cytoplasm at the presynaptic active zone of a central nervous system synapse. Neuron 1:201-209.

Lemke EA, Klingauf J (2005) Single synaptic vesicle tracking in individual hippocampus boutons at rest and during synaptic activity. J Neurosci 25:11034-11044.

Lenzi D, Runyeon JW, Crum J, Ellisman MH, Roberts WH (1999) Synaptic vesicle populations in saccular hair cells reconstructed by electron tomography. J Neurosci 19:119-132.

Lenzi D, Crum J, Ellisman MH, Roberts WM (2002) Depolarization redistributes synaptic membrane and creates a gradient of vesicles on the synaptic body at a ribbon synapse. Neuron 36:649-659.

Lucic V, Yang T, Schweikert G, Forster F, Baumeister W (2005) Morphological characterization of molecular complexes present in the synaptic cleft. Structure 13:423-434.

Marco S, Boudier T, Messaoudi C, Rigaud JL (2004) Electron tomography of biological samples. Biochemistry (Mosc) 69:1219-1225.

Messaoudi C, Boudier T, Lechaire JP, Rigaud JL, Delacroix H, Gaill F, Marco S (2003) Use of cryo-negative staining in tomographic reconstruction of biological objects: application to T4 bacteriophage. Biol Cell 95:393-398.

Moor H (1987) Theory and practice of high pressure freezing. In: Cryotechniques in biological electron microscopy (Steinbrecht RA, Zierold K, eds), pp 175-191. Berlin: Springer.

Ohtsuka T, Takao-Rikitsu E, Inoue E, Inoue M, Takeuchi M, Matsubara K, Deguchi-Tawarada M, Satoh K, Morimoto K, Nakanishi H, Takai Y (2002) Cast: a novel protein of the cytomatrix at the active zone of synapses that forms a ternary complex with RIM1 and Munc13-1. J Cell Biol 158:577-590.

Peters A, Palay S, Webster H (1991) The fine structure of the nervous system. New York: Oxford UP.

Pfenninger K, Akert K, Moor H, Sandri C (1972) The fine structure of freeze-fractured presynaptic membranes. J Neurocytol 1:129-149.

Phillips GR, Huang JK, Wang Y, Tanaka H, Shapiro L, Zhang W, Shan WS, Arndt K, Frank M, Gordon RE, Gawinowicz MA, Zhao Y, Colman DR (2001) The presynaptic particle web: ultrastructure, composition, dissolution, and reconstitution. Neuron 32:63-77.

Pieribone VA, Shupliakov O, Brodin L, Hilfiker-Rothenfluh S, Czernik AJ, Greengard P (1995) Distinct pools of synaptic vesicles in neurotransmitter release. Nature 375:493-497.

Rizzoli SO, Betz WJ (2005) Synaptic vesicle pools. Nat Rev Neurosci 6:57-69.

Rostaing P, Weimer RM, Jorgensen EM, Triller A, Bessereau JL (2004) Pres- ervation of immunoreactivity and fine structure of adult C. elegans tissues using high-pressure freezing. J Histochem Cytochem 52:1-12.

Rostaing P, Real E, Siksou L, Lechaire J-P, Boudier T, Boeckers TM, Gertler F, Gundelfinger ED, Triller A, Marty S (2006) Analysis of synaptic ultrastructure without fixative using high pressure freezing and tomography. Eur J Neurosci 24:3463-3474.

Schikorski T, Stevens CF (1997) Quantitative ultrastructural analysis of hippocampus excitatory synapses. J Neurosci 17:5858-5867.

Schikorski T, Stevens CF (2001) Morphological correlates of functionally defined synaptic vesicle populations. Nat Neurosci 4:391-395.

Schneggenburger R, Neher E (2005) Presynaptic calcium and control of vesicle fusion. Curr Opin Neurobiol 15:266-274.

Schoch S, Gundelfinger E (2006) Molecular organization of the presynaptic active zone. Cell Tissue Res 326:379-391.

Shepherd GM, Harris KM (1998) Three-dimensional structure and composition of CA3-CA1 axons in rat hippocampus slices: implications for presynaptic connectivity and compartmentalization. J Neurosci 18:8300-8310.

Shtrahman M, Yeung C, Nauen DW, Bi G-q, Wu X-I (2005) Probing vesicle dynamic in single hippocampus synapses. Biophys J 89:3615-3627.

Südhof TC (2004) The synaptic vesicle cycle. Annu Rev Neurosci 27:509-547.

Südhof TC, Lottspeich F, Greengard P, Mehl E, Jahn R (1987) A synaptic vesicle protein with a novel cytoplasmic domain and four transmembrane regions. Nature 238:1142-1144.

Takao-Rikitsu E, Mochida S, Inoue E, Deguchi-Tawarada M, Inoue M, Ohtsuka T, Takai Y (2004) Physical and functional interaction of the active zone proteins, CAST, RIM1, and Bassoon, in neurotransmitter release. J Cell Biol 164:301-311.

Takei Y, Harada A, Takeda S, Kobayashi K, Terada S, Noda T, Takahashi T, Hirokawa N (1995) Synapsin I deficiency results in the structural change in the presynaptic terminals in the murine nervous system. J Cell Biol 131:1789-1800.

Tatsuoka H, Reese TS (1989) New structural features of synapses in the anteroventral cochlear nucleus prepared by direct freezing and freezesubstitution. J Comp Neurol 290:343-357.

tom Dieck S, Sanmartí-Vila L, Langnaese K, Richter K, Kindler S, Soyke A, Wex H, Smalla K-H, Kämpf U, Fränzer J-T, Stumm M, Garner CC, Gundelfinger ED (1998) Bassoon, a novel zinc-finger CAG/glutaminerepeat protein selectively localized at the active zone of presynaptic nerve terminals. J Cell Biol 142:499-509.

tom Dieck S, Altrock WD, Kessels MM, Qualmann B, Regus H, Brauner D, Fejtová A, Bracko O, Gundelfinger ED, Brandstätter JH (2005) Molecular dissection of the photoreceptor ribbon synapse: physical interaction of Bassoon and RIBEYE is essential for the assembly of the ribbon complex. J Cell Biol 168:825-836.

Triller A, Korn H (1985) Activity-dependent deformations of presynaptic grids at central synapses. J Neurocytol 14:177-192.

Wagh DA, Rasse TM, Asan E, Hofbauer A, Schwenkert I, Dürrbeck H, Buchner S, Dabauvalle M-C, Schmidt M, Qin G, Wichmann C, Kittel R, Sigrist SJ, Buchner E (2006) Bruchpilot, a protein with homology to ELKS/ CAST, is required for structural integrity and function of synaptic active zones in Drosophila. Neuron 49:833-844.

Wang Y, Okamoto M, Schmitz F, Hofmann K, Südhof TC (1997) Rim is a putative Rab3 effector in regulating synaptic vesicle fusion. Nature 388:593-598.

Wang Y, Liu X, Biederer T, Sudhof TC (2002) A family of RIMbinding proteins regulated by alternative splicing: implications for the genesis of synaptic active zones. Proc Natl Acad Sci USA 99:14464-14469.

Weimer RW, Gracheva EO, Meyrignac O, Miller KG, Richmond JE, Bessereau JL (2006) UNC-13 and UNC10/RIM localize synaptic vesicles to specific membrane domains. J Neurosci 26:8040-8047.

Wilson MT, Farmer MA, Karwoski CJ (1998) Ultrastructure of the frog retina after high-pressure freezing and freeze substitution. J Microsc 189:219-235.

Zhai RG, Bellen HJ (2004) The architecture of the active zone in the presynaptic nerve terminal. Physiology 19:262-270.

Zuber B, Nikonenko I, Klauser P, Muller D, Dubochet J (2005) The mammalian central nervous synaptic cleft contains a high density of periodically organized complexes. Proc Natl Acad Sci USA 102:19192-19197. 